\title{
Round Table: Target Groups, Users, Followers, Fans - The Nature and Potential of Social Data in Archaeology
}

\author{
CARMEN LÖW, Kuratorium Pfahlbauten, Austria \\ ELISABETH MONAMY, ArcheoMuse, Austria \\ FIONA POPPENWIMMER, Natural History Museum of Vienna, Austria \\ HELENA SEIDL DA FONSECA, Kuratorium Pfahlbauten, Austria
}

\begin{abstract}
At the $21^{\text {st }}$ Cultural Heritage and New Technologies conference (CHNT), which took place from November 16th to 18th 2016 in Vienna, Austria, Carmen Löw organized a round table to discuss first experiences with social data from the use of social media in archaeology. The participants presented two Facebook accounts and one weblog owned by a UNESCO World Heritage, a research project and a private company. So far, social data has received too little attention in archaeology. Regardless of the limitations encountered with a user group with special age, sex and other regulations, social data helps us to understand at least a part of our stakeholders better and to adjust the information we offer in social media to their interests. To communicate in a professional manner, it is mandatory to understand who is on the receiving end of the information transportation process. Tools, all well-known and widely used in the world of economics, are often not affordable for scientific research in humanities and so we could mostly only guess who might be listening to us. Since archaeology is widely present in the internet, and since there are Facebook-accounts, websites and weblogs, it is now possible for us to get some reliable information about our followers and supporters. In this article, we provide basic information on communication, with a special focus on communication in the archaeological field, as well as figures on the current use of the Internet. We present data, possibilities for their interpretations and general observations on users, followers and fans in selected tools from the three examples mentioned above.
\end{abstract}

Key words:

Social Data, Communication, Public Relations, Internet, User Data

SDH Reference:

Carmen Löw et al. 2017. Round Table: Target Groups, Users, Followers, Fans - The Nature and

Potential of Social Data in Archaeology. SDH, 1, 2, 627-641.

DOI: $10.14434 /$ sdh.v1i2.23245

Author's address: Carmen Löw, Kuratorium Pfahlbauten, Burgring 7, 1010 Wien, Austria; email: loew@pfahlbauten.at; Elisabeth Monamy, Archeomuse e.U. - Archäologie mit allen Sinnen erleben, Georg-Schicht-Platz 2/5 1210 Vienna, Austria; email: office@archeomuse.com; Fiona Poppenwimmer, Natural History Museum of Vienna, Department of Prehistory, Burgring 7, 1010 Wien, Austria; email: fiona.p@gmx.at; Helena Seidl Da Fonseca, Kuratorium Pfahlbauten, Burgring 7, 1010 Wien, Austria; email: seidl@pfahlbauten.at

Permission to make digital or hardcopies of part or all of this work is granted without fee according to the open access policy of SDH.

(C) 2017 SDH Open Access Journal

Studies in Digital Heritage, Vol. 1, No. 2, Publication date: December 2017 
1:628 C. Löw et al.

\section{INTRODUCTION}

Tools of professional communication are gradually being applied in archaeology. Fortunately, however, many institutions have already begun using the extensive possibilities offered by the Internet for direct communication with the public. Above all, Facebook is used by many, hoping to reach numerous people. Seldom do operators of blogs and Facebook accounts [Bocatius 2016] with an archaeological orientation deal with the question of which target groups can be reached via these channels and which content is suitable in a particular case [Oswald 2016]. Indeed, this goes beyond archaeology and applies to the entire cultural sector in Austria and Germany, where strategic orientation of social media work is still rare [Bocatius 2016].

At the same time, and with the help of current analytic tools on the internet, it is easy to find out who is interested in the adjusted content and how it needs to be configured in order to achieve the greatest possible impact. The "Round Table on Target Groups, Users, Followers and Fans" was therefore specifically concerned with the "Nature and Potential of Social Data in Archaeology."

\section{BASICS OF COMMUNICATION WITH A SPECIAL FOCUS ON COMMUNICATION IN ARCHAEOLOGY}

In order to better understand the value of the information that analytic tools provide about our followers and fans, it is helpful to deal with the basics of communication. The word communication is derived from the Latin communicare" and essentially refers to the exchange of information. A simplified model of the communication process, developed by the founders of information theory Warren Weaver and Claude Elwood Shannon, shows very clearly why it is indispensable to know the recipients of your own messages [Shannon 1948, Shannon and Weaver 1949].

In their model, the process of information transfer is reduced to the most essential [ Shannon 1948]. The starting point is the desire to forward information from a transmitter to a receiver. In order to transmit the information, the transmitter must first encode it. This means that he/she translates the content into characters, for example in words or images. This code is then sent to the receiver via a channel. The receiver must decrypt the character system selected by the transmitter in order to obtain the information. Decoding by the receiver can only be successful if the selected character system is understandable for this purpose. This is the responsibility of the sender, who must take into account the knowledge of the receiver during encoding and must therefore know his/her state of knowledge first. Disturbances during transmission-shown as a channel in figure 1-can also lead to the failure of the information transfer.

The scientifically substantiated target group surveys for archaeological research are mostly searched in vain. ${ }^{1}$ Even common market research tools, which are widespread in the economy (such

\footnotetext{
${ }^{1}$ Works like Raimund Karl's [Karl et al. 2016] have only limited significance because of the arbitrariness of the group of respondents. In order to be scientifically comprehensive, the sample would have to be selected methodically. The results, which have already been achieved by the work of R. Karl et al. with random samples, emphasize the need for intensive research in this area.
} 
as Sinus Milieus), are largely unknown. ${ }^{2}$ It would appear that this is a consequence of the high costs such professional tools incur. From information derived from the little that is publicly available and free of charge, and is based on the observations of one's own stakeholders, ${ }^{3}$ it can be assumed that archaeology mostly appeals to conservative and traditional people who have a strong reference to their country and who are primarily interested in archaeology when the subject matter is directly connected with their own living environment.

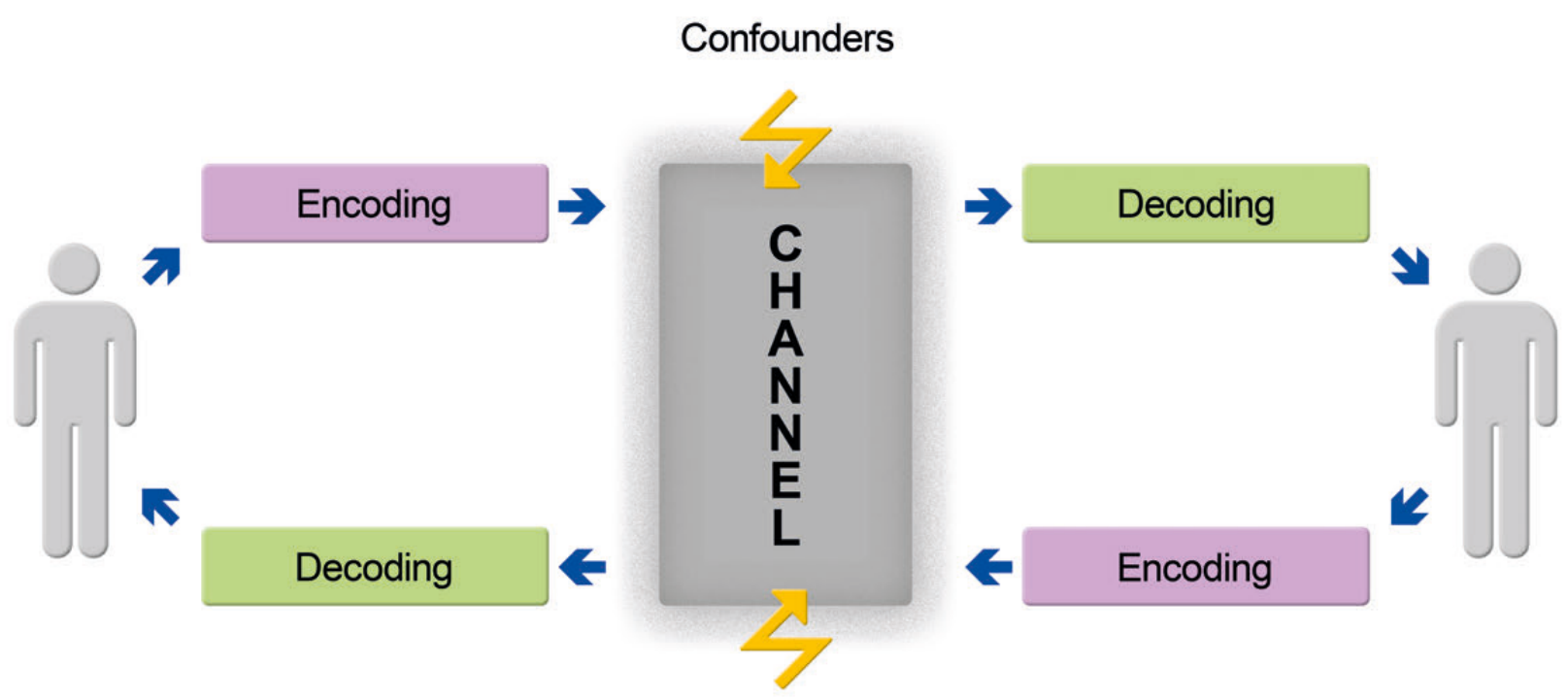

\section{Confounders}

Figure 1. Simplified representation of the communication process according to Shannon and Weaver.

It is becoming evident that adventurous and experience-orientated people are dealing with archaeological issues in a rather uncomplicated way, provided that they encounter the subject in the form of archaeotechnique or experimental archaeology. It is also assumed that people who are primarily consumption-orientated and generally not interested in education can hardly be reached with archaeological content. However, we know nothing about the group commonly called the "center middle class."

\footnotetext{
${ }^{2}$ Already in 2007, journalist and archaeologist Diane Scherzler presented the Sinus Milieus in the "Archaeological Information" and suggested that target group typologies should generally be used as a means of communication with the public [Scherzer 2007]. To date, however, the use of target group typologies in the archaeological area is almost exclusively limited to museum facilities. For example, the Carnuntum archaeological park presented such an analysis during the network meeting "DonauLimes als UNESCO Weltkulturerbe - Chancen und Wegbereiter" at the Schlossmuseum Linz on September 21, 2016. Here, however, the main focus was on marketing aspects that increase visitor numbers. Regarding the usage of target group typologies for public relationship management, see [Löw 2016].

${ }^{3}$ The term "stakeholder" refers to all those who are affected by our actions. Stakeholders can be affected by archaeological research for a variety of reasons. This must neither be wanted by them, nor must these people necessarily be interested in archeology or even have a clear idea of the intended purpose of archaeological research.
} 
Information that can be obtained through communication on the web about people who are interested in archaeological contents is thus a first, still very thin, but reliable, data base. However, data on online active and interested individuals are subject to their own parameters. They are therefore not representative of the entire group of all stakeholders or even the so-called general public. This is revealed, among other things, by studies on online use.

Undoubtedly, these data are characterized by the different usage practices of the Internet within different generations. As a rule, target groups are summarized in about 10-year steps in professional communication. 84.3\% of people used the Internet in Austria in 2016. ${ }^{4}$

Nearly $100 \%$ of people under the age of 34 used the Internet on a regular basis. In the two age groups above that, 35 to 44 and 45 to 54 years, it is still about $95 \%$ and $83 \%$ respectively. The age group up to 64 years uses the Internet almost regularly up to $71.7 \%$ and even the 65 to 74 -year-olds still reach $51.3 \%{ }^{5}$ Thus, in principle, all age groups are well within reach via this medium. In addition, mobile Internet use has been increasing continuously for years. This observation has also been made in the "Stiegenblog" of the Hallstatt research [Löw et al. 2016].

Since the Internet is a relatively young medium, there is no standard from which conceptual questions can be derived. Meanwhile, the first parameters of professional communication on the Web have emerged, at least for the areas of PR and marketing [Schindler 2015].

\section{EXPERIMENTAL ARCHAEOLOGY IN SOCIAL MEDIA - THE EXAMPLE OF ARCHEOMUSE}

ArcheoMuse ${ }^{6}$ is a registered company that was founded in 2015. Its focus is to give people a glimpse of the daily aspects of life of various historic periods through ancient cooking workshops. Such a cooking workshop is a way of travelling through time by using historic cooking pots and thus experiencing archaeology differently. This approach to archaeology and history should enable more and more people to learn about ancient civilizations in a comfortable and amusing yet scientifically rooted way. The target groups are hobby cooks, who are looking for a culinary challenge, and history lovers or enthusiasts searching for a new approach to history and archaeology; both groups are made up of adult men and women. Another target group consists of (mostly Latin) classes, whose students are eager to revive the Roman way of life. The innovative concept is to offer experimental archeological workshops in a non-scientific atmosphere for a wide audience in Austria. The use of social media has been of great importance in both calling attention to these courses and endorsing them.

\footnotetext{
${ }^{4}$ Statistic Austria, households with computers, Internet access and broadband connections; persons who use computers and the Internet, as well as online shoppers from 2002 to 2016.

http://www.statistik.at/web_de/statistiken/energie_umwelt_innovation_mobilitaet/informationsgesellschaft/ikteinsatz_in_haushalten/022206.html [Retrieved on 5.1.2017]

${ }_{5}^{5}$ Statistic Austria, households with computers, Internet access and broadband connections; persons who use computers and the Internet, as well as online shoppers from 2002 to 2016. http://www.statistik.at/web_de/statistiken/energie_umwelt_innovation_mobilitaet/informationsgesellschaft/ikteinsatz_in_haushalten/073636.html [Retrieved on 25.1.2017]

${ }^{6}$ www.archeomuse.com [Retrieved on 27.1.2017].
} 


\subsection{Social media presence}

In the beginning, ArcheoMuse had a Facebook group with 230 members and a Facebook page with 180 "likes." After gainingmomentum, the page is being updated on a more regular basis and ArcheoMuse even has a Google+ (nearly 20 followers), an Instagram (26 followers) and a Twitter (24 followers) account. The creation of a YouTube channel is still in progress; only one short movie has been posted so far. ${ }^{7}$ Based on its presence and dissemination in social media, it should be pointed out that Facebook ${ }^{8}$ is definitively the main and most important media outlet to endorse ArcheoMuse.

\subsection{Postings on Facebook}

Postings on Facebook occur infrequently, depending on events relating to the ancient cooking workshops (once a month) and on new findings concerning food in antiquity which are linked on the page. Oddly enough, the most popular postings relate to scientific work, their results and their impact nowadays, as well as information regarding upcoming events.

ArcheoMuse's Facebook page attracts a very broad-based and often unexpected audience, and not necessarily the same groups targeted in print media.

Postings are made around the clock, although the site is less active between 1:00 and 6:00 am. On an average, a post is read by 250 to 300 people (Fig. 2). Some, however, such as the one about a beer recipe found in China dating to 5000 years ago or the announcement of the participation at CHNT 21, were read by over 500 people.

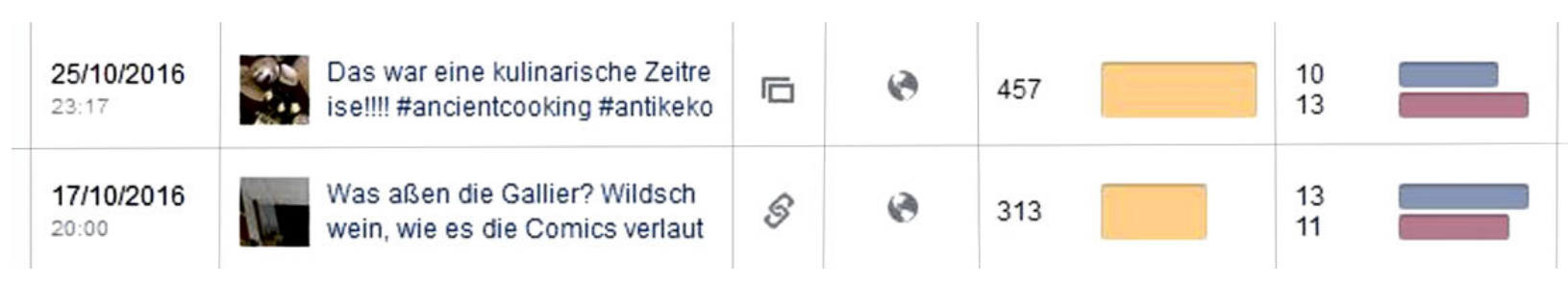

Figure 2. Postings on Facebook.

Surprisingly, pictures of past events generate more "likes" and views on Facebook than on Instagram. Only 5 to 10 out of 250 to 300 people, approximately 3\%, who have viewed those pictures, also reacted to them by commenting.

\subsection{Impact of the use of social media}

When E. Monamy started presenting ArcheoMuse and its work on social media, she expected to reach many more people on a daily basis. It was quite disappointing to see the statistics. Currently, one year later, she is happy about how things have evolved; the audience has grown, and more and more people react to postings through likes and comments (Figure 3). Even though only one person

\footnotetext{
${ }^{7}$ All data stem from January15, 2017.

${ }^{8}$ www.facebook.com/archeomuse
} 
has booked an ancient cooking workshop through social media, the name ArcheoMuse is no longer an unknown concept. During conferences with accompanying food tastings, Monamy met several people who had heard about the ancient cooking workshops, showed interest in them within their own social networks and were curious about them. Therefore, Facebook remains a great way to inform not only target groups but a much broader audience.

Page summary Last 28 days *

Export Data ๒

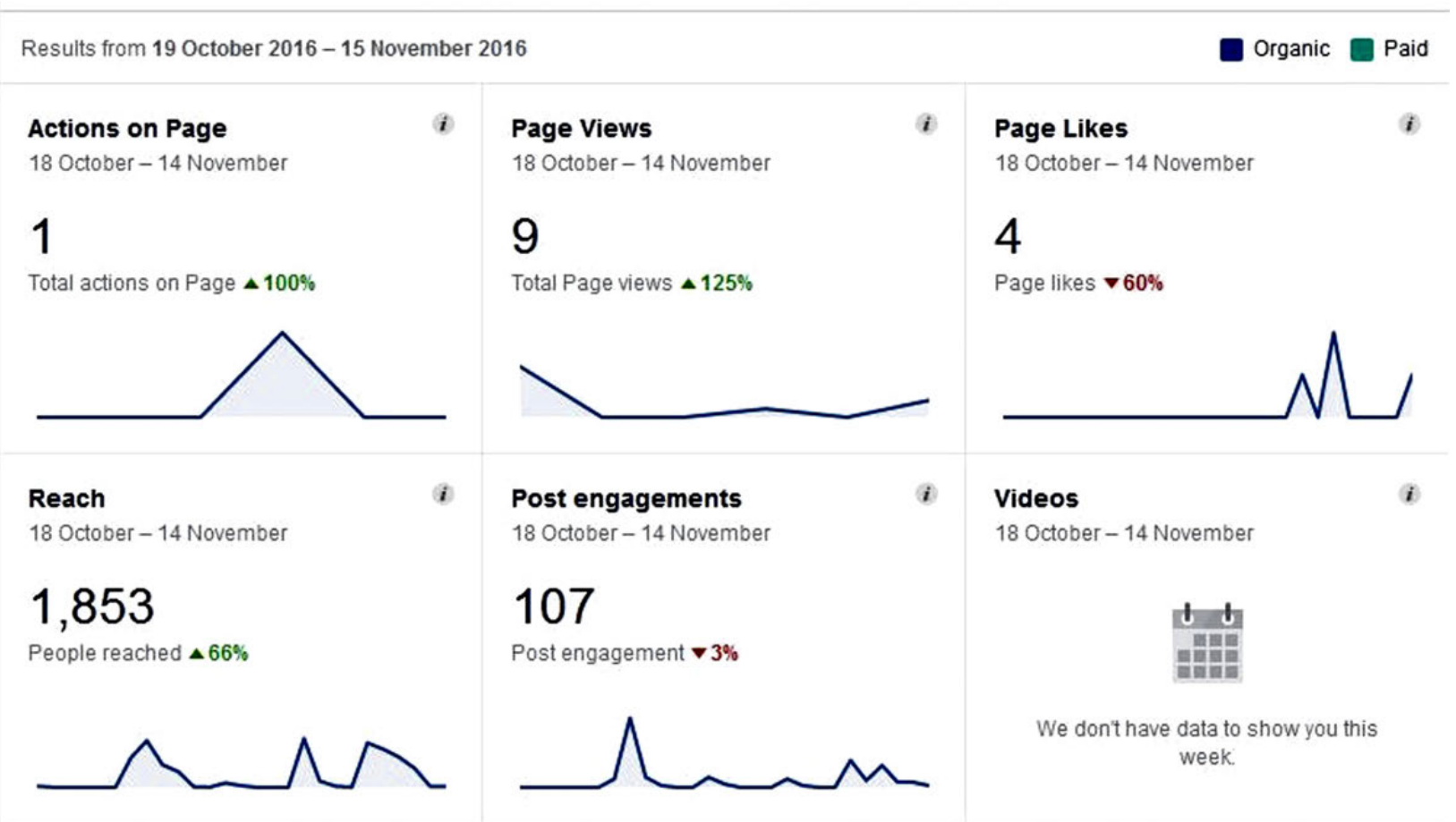

Figure 3. Statistics of the Facebook account ArcheoMuse.

While current statistics concerning the use of social media for disseminating information on ArcheoMuse indicate an increased interest in this approach to archaeology, it does not yet reach some potential clients. However, this information strengthens ArcheoMuse's efforts and success in reaching a wide audience. 


\section{THE USE OF WEBLOGS TO IMPART SCIENTIFIC RESULTS: THE EXAMPLE OF THE HALLSTATT RESEARCH}

In 2014 the Hallstatt research group founded two weblogs, in addition to its official website. ${ }^{9}$ One of them, the so- called "Stiegenblog"10 (or "staircase weblog") was provided on the occasion of thedismantling, examination and reconstruction of the Bronze Age wooden staircase from the Hallstatt salt mine.

\subsection{Aims and target groups}

The main goal of this weblog was to announce current information about the staircase to the general public [Löw 2016]. The target groups were both professionals in archaeology and its related disciplines, as well as people who are not scientists, but interested in the Hallstatt research. The weblog is also particularly of interest to locals of the regions Hallstatt and Salzkammergut. Therefore, one of its ambitions is to improve the reputation of the Hallstatt research in the region, as well as to impart information on topics normally unseen by public.

The weblog is a reliable, always available and current source of information for journalists. This increases the chances for the Hallstatt research to be mentioned in media.

The purpose of reaching as many people as possible, not just scientists, made German as the language of the blog quite obvious. It was also good to maintain the very personal writing style that is typical of weblogs [Löw et al. 2016].

\subsection{Facts and figures}

As a provider, blogger.com by Google.Inc., was chosen, since it is free of charge and without advertising, and it can be operated without HTML skills. In addition, it offers a mobile version of the weblog, which is essential due to the increasing number of people using mobile devices. A downside of this provider is the limited possibilities of the analytic tools.

The layout of the weblog was kept in the corporate design of the Natural History Museum Vienna, with a noticeable placement of the logos of all research partners.

People visited the weblog frequently even before current postings were uploaded. But with the increasing number of current postings since January 2014, a constant increase in visits has beennoticed. ${ }^{11}$

The weblog reached its maximum range in February 2015, during the reconstruction of the staircase. The number of visits increased from about 600 per month to about 4000 in the month of February, due to the more frequent release of postings and the current topics. Also, there was a press release published by the Natural History Museum Vienna in February, which mentioned the weblog. ${ }^{12}$

\footnotetext{
${ }^{9}$ www.nhm-wien.ac.at/hallstatt

${ }^{10}$ www.hallstatt-forschung.blogspot.co.at

${ }^{11}$ Status 7.11 .2016

${ }^{12}$ Status 7.11.2016
} 
The current number of visits per month is about 1100, with a total number of viewings of about 45,000 since the weblog went online. ${ }^{13}$ Unfortunately, there are barely any facts and figures about archaeological weblogs to compare it to, because this topic still belongs to the realm of "special interests." Probably the most famous archaeological weblog in the German-speaking area, called "Archäologik", registers about 12,000 visits per month. This comparison shows that the Hallstatt weblog is still one with a smaller range [Löw et al. 2016].

More than half of the users are accessing the Hallstatt weblog via Facebook, where every posting is promoted separately. Since there is no official Facebook account of the Hallstatt research, the postings are announced on the accounts of the editor, the authors and the staff. They are also shared on the corporate accounts of the Natural History Museum Vienna and those of the research partners. Since the analytic tools on blogger.com are not very detailed, not all visits are clearly traceable, though it shows that besides Facebook, the websites of the Natural History Museum and the one of the main partner, Salzwelten $\mathrm{GmbH}$, are responsible for a lot of visits to the weblog. An increase in the access rate was always noticed whenever there was a press release mentioning the weblog or

any other appearance of the Hallstatt research in media [Löw et al. 2016]. This opportunity can be used to release special topics that seem especially important to the editor or the management, soon after being mentioned in media, in order to to guarantee as many readers as possible.

$50 \%$ of the readers come from Austria, followed by Germany, USA, Russia, Ukraine and Switzerland. Unfortunately, the analytical tools are no more specific with that, so one cannot tell, for example, from which Austrian province the readers come, which would be very interesting for us.

\subsection{Authors and writing style}

Every person on the staff is encouraged to write texts for the weblog. This presents the topics from various different and very personal perspectives, which reflects the diversity of Hallstatt research. The analytical tools do not point out clearly which topics are the most interesting for people to read, because the access rate is influenced by many other parameters [Löw et al. 2016].

For the authors, mainly unexperienced with weblogs, the main difficulty is to find the right writing style. The texts have to be scientifically correct, but at the same time entertaining-a task which is not always easy to accomplish. . This usually very personal style allows an individual perspective on the topics that are personally important to every single author. Often these are aspects of the archaeological work that is normally not mentioned in scientific publications, but which is also quite interesting for most readers. For the editor, this personal style is sometimes challenging, because corrections are not easy to make or to be accepted by the authors.

\subsection{Conclusion}

The experience of the Hallstatt weblog points out some clear benefits and downsides for this way to impart scientific work to the public.

\footnotetext{
${ }^{13}$ Status 7.11.2016
} 
Especially for young staff members, who are unexperienced in writing, a weblog is a good opportunity to practice for further publications. At the same time, researchers get a very straight feedback on their work and their texts, via comments on the weblog and social media, access rates and personal conversation with readers.

While working on it, one 'sown research is arranged into a text in the author's mind, and everyone has to take appropriate pictures of the work, and thus each has to think about it from many different angles.

As mentioned before, research is often shown from a very personal perspective in a weblog, and topics are brought up for which there is no room in scientific publications. That makes it very interesting for the authors to write and for the audience to read.

A weblog is an easily accessible, reliable and current source for journalists, which can help to gain more attention in print media. Through well-timed interaction between the weblog and other media it is possible to push certain topics. It is also possible, via the weblog, to reach people who normally would not read too much about science in classic media.

But despite all the benefits, one should not forget the expense and effort required to provide and advertize a weblog. Because of the public access to the information, the pressure to publish in print can decrease. But so far, weblogs cannot replace scientific publication in print media. Weblogs are still not fully accepted for publishing the results of scientific research, especially in humanities fields like archaeology.

But due to our experience with the Hallstatt weblog, there are many more positive effects than downsides, and we hope that this outlet for presenting our research to the public will become even more accepted in the next few years.

\section{THE FACEBOOK ACCOUNT OF THE UNESCO WORLD HERITAGE “PREHISTORIC PILE DWELLINGS AROUND THE ALPS" IN AUSTRIA}

The Kuratorium Pfahlbauten is entrusted with the management of five prehistoric settlements, all submerged in lakes, that are part of the international and serial UNESCO World Heritage "Prehistoric Pile Dwellings around the Alps." The Kuratorium is particularly committed to an active communication and interaction with the public-a task that results from the World Heritage Convention, ${ }^{14}$ the general objective of UNESCO and a position paper of all nine Austrian World Heritage Sites. ${ }^{15}$

\subsection{Target}

The Kuratorium Pfahlbauten specifically employs Facebook to create a more intelligible access to the topic of "pile dwellings." This channel is used, among other things, to make current activities of

\footnotetext{
${ }^{14}$ http://whc.unesco.org/en/conventiontext/

${ }^{15}$ http://pfahlbauten.at/system/files/downloads/wh_in_oe_positionspapier_unterzeichnet_6.4.2016.pdf
} 
staff members visible, to promote events, to inform people about the work of international partners within the UNESCO World Heritage of the prehistoric pile dwellings, and to convey archaeological contents in general [Bocatius 2016]. In particular, this relates to creating a more personal and human connection with the employees of the Kuratorium in order to remove the often naturally projected impersonal character of an organization. In addition, the Facebook account serves as a communication channel through which the Kuratorium can be contacted barrier-free, directly and at any time. So far, the account has exclusively grown organically. It was decided not to place purposeful advertisement or other commercial offers, since such aids can only reach the desired target group to a limited extent and a rather organic development is regarded as more sustainable.

\subsection{Facts about follower: numbers, sex and age}

The Facebook account @pfahlbauten.at ${ }^{16}$ has existed since 2013. The number of "likes" initially rose slowly. However, since August 2015, efforts have been focused on building up its coverage. To this end, a series of invitations have been sent out twice. Both originated from the private accounts of two administrators. Based on the assumption that there are strong ties to the content and/or the initiators themselves in the network, two employees invited their entire private Facebook contacts to like the Kuratorium Pfahlbauten's Facebook page. The function "Invite friends to tag this page with Like" was used for this purpose.

The first round of invitations in August 2015, as well as a second one in April 2016, led to a sudden surge as shown in Figure 4. Since then, responses to individual contributions have been regularly reviewed. If someone responds to a single post but the page is not "liked" by this person, Facebook offers the possibility of inviting that person to tag the page with "like,", even if there is no private contact between the two parties. By December 2016, the one thousand marks was exceeded; thus, the number of "likes" has almost tripled in less than one and a half years.

\section{„Gefällt mir"-Angaben für die Seite insgesamt (Stand heute: 1.056)}

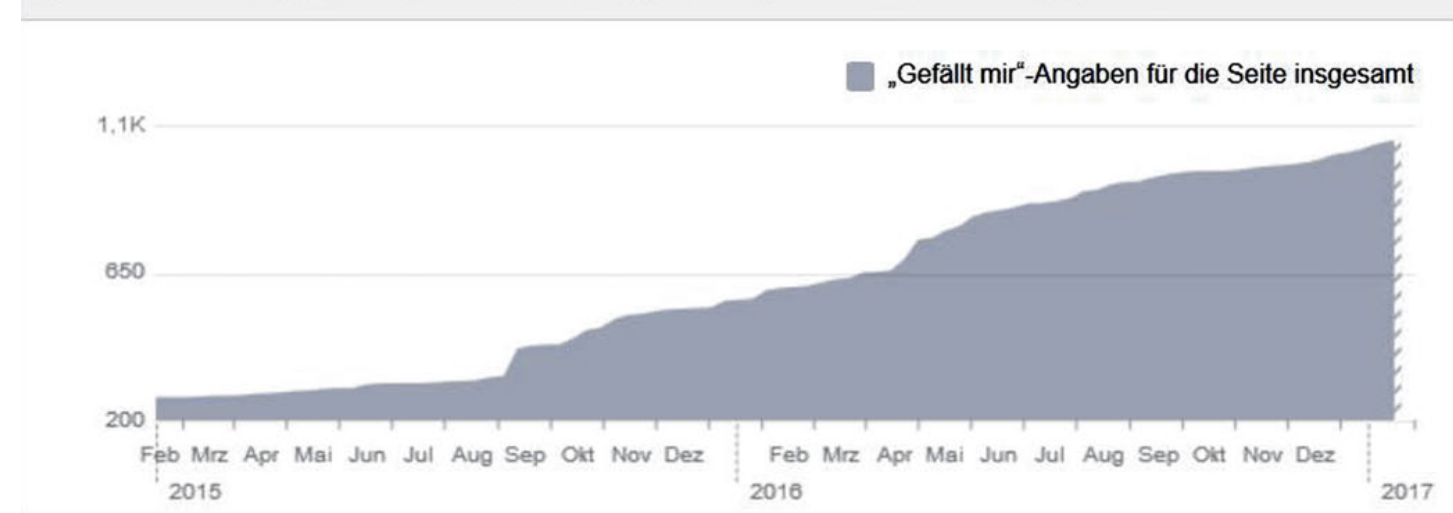

Figure 4. Increase in the number of "likes."

\footnotetext{
${ }^{16}$ https://www.facebook.com/pfahlbauten.at/
} 
Overall, there is a balanced representation between men and women among the fans of the site; it varies between $49 \%$ and $51 \% .{ }^{17}$ However, differences become visible in the willingness to interact; it is significantly higher among women, currently $55 \%$ compared to $43 \%$. A further imbalance is evident in the age groups. 17\% of female fans belong to the age group 25-34 years, a group that consistently accounts for the strongest contributor. The strongest group among men is that of the 35-44 year olds. The age groups of both sexes under 24 years and over 55 years are all within the single-digit range. $56 \%$ of all fans are between 25 and 44 years old.

Among other things, this data led to the choice of a rather informal way of communication on this channel. Administrative offices and titles are usually not mentioned, and postings and comments from the editorial staff may have a cheeky note despite the dignity that resides in UNESCO World Heritage sites.

The majority of fans currently come from Austria (649 persons); thus, Austria is ahead of Germany with 205 people. Switzerland, a country where German is spoken in many parts and pile dwellings are a more well-known and also better-explored phenomenon than in Austria, has 21 fans and is thereby behind Italy with 28 fans. Slovenia is in fifth place with a total of 15 fans. Of the six countries that participate in the UNESCO World Heritage "Prehistoric Pile Dwellings around the Alps," only France is not represented in this group. With a total of five fans, France is number fourteen on the list and thus far behind other partner countries; an existing language barrier may partially affect all partner countries. This ranking may be due to the limited presence of the French part of the UNESCO World Heritage on the Internet in general and on Facebook in particular.

Among the regional populations, the rather small community of Keutschach am See, with fewer than 2500 inhabitants, shows a high online activity with 16 recorded fans. Therefore, it is positioned immediately behind the larger cities of Vienna (303 fans), Klagenfurt (39), Graz (25), Linz (22) and Salzburg (21). But members of other municipalities in which the five Austrian pile-dwelling heritage sites are located are also informed about the activities of the Kuratorium via Facebook.

The quite high number of fans from Vienna (303 fans) can probably be traced back to the local concentration of scientists and students active in, for example, the fields of archaeology, dendrochronology and archaeobotany. However, the assumption that many experts who conduct research in nearby or related areas follow the Facebook account of the Kuratorium cannot be derived from this figure alone. Already several employees of the Kuratorium have repeatedly made the observation that colleagues at home and abroad, and with whom no active collaborations are in progress, are indeed well informed about the activities of the Kuratorium. A better visibility of current activities within the research community can, among other things, lead to new cooperation and initiate an international exchange of expertise on individual topics; indeed, it has already done so.

\subsection{Times when fans are online}

Statistics provided by Facebook for corporate pages free of charge show that fans of the account are most active on Fridays. 953 of them are online that day. ${ }^{18}$ The lowest activity occurs on Mondays

\footnotetext{
${ }^{17}$ These and the following numbers in this section were retrieved on 28.1.2017.

${ }^{18}$ These and the following numbers in this section were retrieved on 28.1.2017
} 
(906). Postings which ought to have a particularly high range and are not time sensitive are therefore launched on Wednesdays (943), Thursdays (944) or Fridays. In the course of the day, a slightly increased activity can be observed around noon on Mondays and Tuesdays. On Wednesdays and Thursdays, most fans are online at $6: 00 \mathrm{pm}$ and $7: 00 \mathrm{pm}$. On the whole, the online activity of fans is distributed fairly evenly throughout the day between $7.00 \mathrm{am}$ and $9.00 \mathrm{pm}$, so that information can be posted at any time within this time frame.

\subsection{Coverage and Topics}

The Kuratorium has been posting since August 2015, usually once a day. With more regular postings and the growing number of fans the range increased strongly. The number of people who have seen the postings has risen from an average of $84.26^{19}$ to $635.68^{20}$ persons (Figure 5). However, it appears that phases with a particularly high range are usually followed, very abruptly, by phases with a particularly low range. Reasons for this have not yet been determined. A change in the frequency of postings cannot prevent this, nor will measures to increase the attractiveness or the interaction potential either. The loss of coverage could be compensated for by advertisements offered by Facebook. This possibility has not yet been adopted by the Kuratorium, since the range usually rises to normal again after a short time.

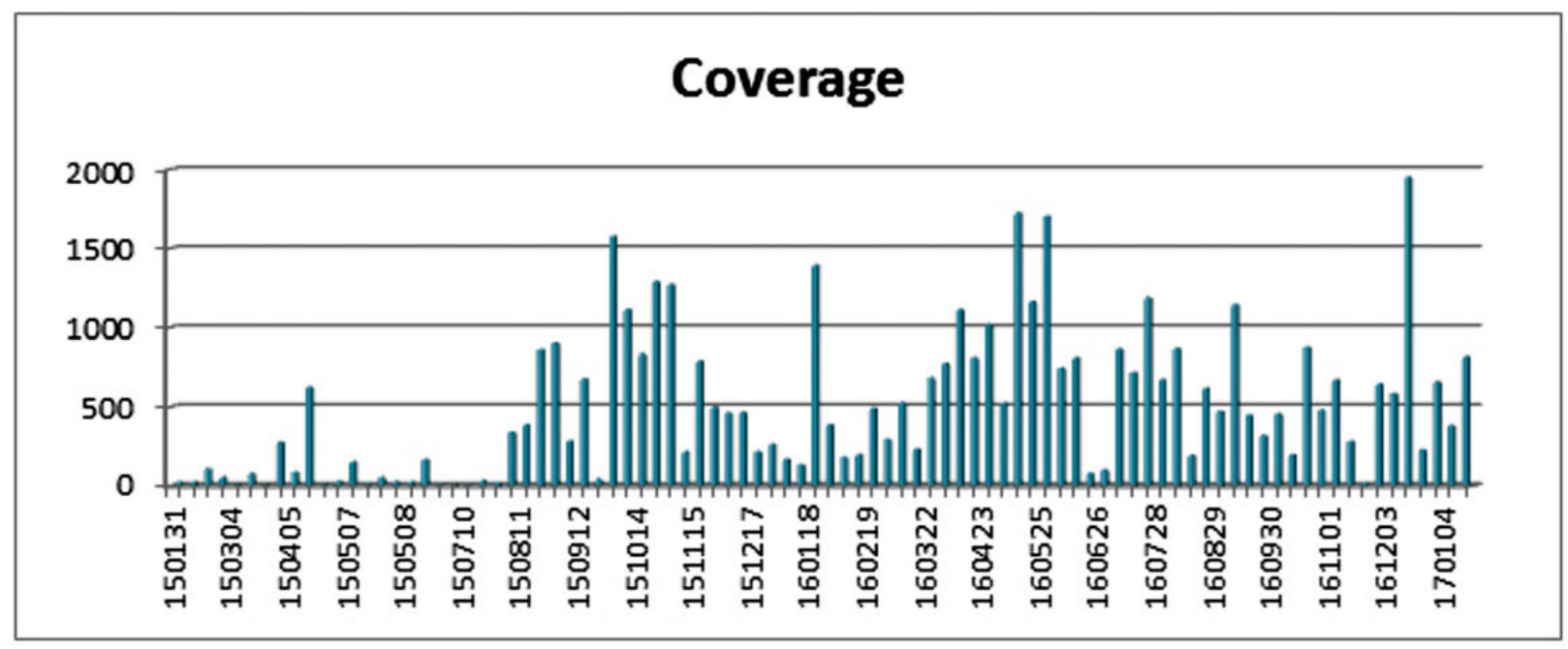

Figure 5. Increase of coverage.

\section{DISCUSSION}

"There will always be a need for communication, one cannot not communicate!" Even if a person remains silent during a discussion, this person has nevertheless said something [Watzlawick et al.

\footnotetext{
${ }^{19}$ Average from January to July 2015.

${ }^{20}$ Average from August 2015 to January 2017.
} 
2011]. Thus, a topic may be deliberated well, whether one chooses to participate in a conversation or not. This particular concept of communication also becomes visible in the example of Facebook. If one opts against the use of Facebook, others will define the image of archeology on this venue with their contents. The Kuratorium Pfahlbauten, for example, has deliberately chosen a Facebook page "Pile dwellings in Austria," not least to determine the contents concerning the prehistoric pile dwellings but also to participate in discussions about the UNESCO World Heritage.

And this subject is much talked about on Facebook.Numerous other Facebook sites on the matter of prehistoric pile dwellings already underline the general interest: "Prehistoric pile dwellings around the Alps," ${ }^{21}$ International Facebook page of the UNESCO World Heritage; "Museo delle Palafitte del Lago di Ledro," ${ }^{22}$ Italian Facebook page of a Palafittes Museum; "V deželi koliščarjev," ${ }^{23}$ Slovenian Facebook page of a Palafittes Museum; "Pfahlbau," ${ }^{24}$ Home Association Facebook site of the Upper Austrian pile dwellings; "Pfahlbauten Museum Unteruhldingen Bodensee," ${ }^{25}$ German Museum Facebook page of a Palafittes Museum; "4.000 Jahre Pfahlbauten," ${ }^{26}$ German Facebook page of a large exhibition about the Prehistoric pile dwellings around the Alps,... just to name a few.

The use of this social media channel offers, in addition to the possibility of making your own work more visible, the advantage of expanding your own professional network. Providing this necessary transparency means that a mutual trust to stakeholders-advocates and opponents-can be established and maintained. This direct line of contact to the research environment allows rapid response to changes and promotes the emergence of new partnerships for further (supra-regional) research projects. Funding bodies, sponsors and supervisory boards also profit from a constant disclosure of the research efforts, as the status of the projects can always be traced.

With regard to the "Staircase blog" of the Hallstatt research, this disclosure of research efforts was already clearly and frequently met with appreciation by the cooperation partners and also actively supported in social media.

In times of Big Data, there are a number of analytic tools available to enhance the alignment of the strategy with factual real-time data. Facebook Insights always provides information about the success of implemented measures and is thus suitable for monitoring public opinion and identifying opinion leaders. Content can thus be better adapted to the target group and concepts can be optimized.

Another aspect that is becoming more and more present on Facebook is the transmission of messages between users. In many countries, Facebook is already one of the top sources for the preselection of news items. In this respect, there is a growing necessity for scientists to actively make their own contributions and to share interesting articles and announcements with their fans.

In addition to the constant editorial work, the many far-reaching possibilities gained by the use of online marketing constitute an enormous and significant advantage. As a result, large and highly

\footnotetext{
${ }^{21}$ https://www.facebook.com/ICGPalafittes

${ }^{22}$ https://www.facebook.com/palafitteledro

${ }^{23}$ https://www.facebook.com/vdezelikoliscarjev

${ }^{24}$ https://www.facebook.com/PfahlbauamAttersee

${ }^{25} \mathrm{https}$ ///www.facebook.com/pfahlbauten

${ }^{26}$ https://www.facebook.com/pfahlbauten2016
} 
specific target groups can be reached at low cost and information about events, projects, surveys, petitions, locations and one's own content can be disseminated.

At this point, however, it must be noted that the use of social media channels seldom produces the desired effect without a well-thought-out communication concept or a PR strategy. In the daily work routine of an archaeologist, the maintenance of a website, a blog or a Facebook page is often regarded as a secondary activity, which does not require a special qualification or even engagement with its content. In this case, the half-hearted use of social media channels quickly becomes visible. Consequently, it loses more and more in quality and thus in its effect. The utilization of social media has to be integrated into the everyday working practices of scientific research and needs planning and time, as has been elaborated especially in the case of the "Staircase Blog" of the Hallstatt research.

It is therefore necessary to be aware that a methodical use of websites, blogs and Facebook changes the mode of operation within the whole team. In order to edit the pages with content, appropriate visuals and texts are needed. Within the organization of the Kuratorium Pfahlbauten, for example, the entire excavation team is required to take beautiful ambiance pictures, to document interesting work steps and to compile stories about their activities. This is made easier if one person takes care of the editorial support of the social media channels, and helps the team by reminding them of the content required for the next days at the beginning of the week. For example, during communicative support of an excavation and the initial release of numerous postings about finds management, it might be advisable to publish specific contributions from the excavation itself. It has proved useful to collect some buffer-posts in the run-up to more intensive communication phases, i. e. during an excavation campaign. This, in turn, gives the team some necessary breathing room. Current postings from an excavation, be they blog posts or on Facebook, remain an additional task of the team, for which the necessary time must be granted. Otherwise, the communication work is an additional workload that creates only unrest in the team.

One downside, especially of weblogs, is that the pressure for researchers to publish scientific results decreases as the information has already been generated and is accessible to the public. Particularly in the Humanities, i.e. archaeology, the weblog as a medium to convey scientific knowledge has not fully asserted itself yet, especially among fellow researchers. Therefore, it cannot replace expensive scientific publications in print.

Based on our experience with the Hallstatt weblog and the Facebook accounts of ArchaeoMuse and the Kuratorium Pfahlbauten, the positive effects of their implementation clearly outweigh the negatives. In view of this, we look ahead to the future with confidence that this manner of presenting our research to the public will become more widely accepted in the next few years.

Archaeologists have to approach the public in a more casual way, trying to avoid making wrong or silly statements referring to movies or fictional literature. It is indispensable to write short and comprehensible sentences, especially in German, to convey scientific knowledge to the public. Contrary to the disbelief of some colleagues that this is a proper and adequate way for us archaeologists to promote our work, statistics clearly show the success of social media as a platform to impart scientific knowledge. Therefore, we will continue our pursuit of reaching as many people as possible in this manner. 


\section{REFERENCES}

Bianca Bocatius. 2016. Museale Vermittlung mit Social Media. Theorie - Praxis - Perspektiven. Düsseldorf (2016) 1-483. DOI: http://dx.doi.org/10.11588/ai.2016.1.33572

Raimund Karl et al. 2016. Archäologie ist wichtig: Archäologische Interessen der österreichischen Bevölkerung. In Fundberichte aus Österreich 53, Vienna: 2014 (2016), 41-153.Carmen Loew et al. 2016. Der Stiegenblog. Ein Weblog der Hallstatt-Forschung. Archäologie Österreichs 27, 1 (2016) Vienna, 36-43.

Carmen Loew. 2016. Example for Stakeholder Values in Hallstatt Research - Archaeology from the Perspective of Public, Economics and Politics. CHNT 20, Conference on Cultural Heritage and New Technologies (2016). Vienna.

Kristin Oswald. 2016. Hand in Hand. Forschung und Vermittlung in der digitalen Archäologie. In: Archäologische Informationen 39 (2016), 77-85.

Hans Reschreiter et al. 2015. Hallstatt goes online - Die Website der Hallstatt Forschung. In Archäologie Österreichs 26,1 (2015), 22-24.

Claude E. Shannon. 1948. A Mathematical Theory of Communication, Bell System Technical Journal, Vol. 27, 379-423, 623-656.

Claude E. Shannon, C.E. and Warren Weaver. 1949. The mathematical theory of communication. Urbana: University of Illinois Press.

Diane Scherzler. 2007. Sein Publikum ernst nehmen - Der Blick einer Journalistin auf den Umgang mit der breiten Öffentlichkeit. In Archäologische Informationen 30, 1 (2007), 111-120.

Marie-Christine Schindler and Tapio Liller. 2012. PR im Social Web. Das Handbuch für Kommunikationsprofis. 2. Aufl., Köln.

Paul Watzlawick et al. 2011. Menschliche Kommunikation: Formen, Störungen, Paradoxien. 12. unveränderte Auflage. Bern: Verlag Hans Huber, 1-317.

Received January 2017; revised July 2017; accepted August 2017. 